\title{
Iconicity in grammatical variation
}

\author{
Takashi Fujiwara ${ }^{1}$, Fuminori Nakamura ${ }^{2}$, Daisuke Suzuki ${ }^{1}$ \\ ${ }^{1}$ Faculty of Foreign Studies, Setsunan University, Japan \\ ${ }^{2}$ College of Liberal Arts and Sciences, Kitasato University, Japan \\ https://doi.org/10.36505/ExLing-2019/10/0024/000386
}

\begin{abstract}
This study examines the form-function relation of prepositional phrases, taking up the use of of interest as a sample case. It is well known that prepositional phrases such as this function like adjectives. By conducting a questionnaire-based survey, we investigated two predictions: (i) whether a formal or real subject filled the Subject slot in a sentence, and (ii) whether the expressions co-occurred with modal verbs. The results of the analysis demonstrate that both variables and their combination have evident effects on the choice between the two alternatives, and these can be interpreted in terms of the iconic principle. The results of this analysis contribute to ongoing discussions about iconicity theory and its applications to related fields.
\end{abstract}

Key words: prepositional phrases, synonymy, questionnaire-based survey, iconicity

\section{Introduction}

This paper examines prepositional of-phrases and their synonymous expressions, paying particular attention to pairs of of-phrases and adjectives. According to Quirk et al. (1985: 732), prepositional phrases are nearly equivalent in meaning to adjective or noun phrases that function as complements in some cases, as shown in examples $(1 \mathrm{a}, \mathrm{b})$ :

(1) a. That is of no importance.

b. That is unimportant. (Quirk et al. 1985: 732)

Biber Johansson, Leech, Conrad (1999) and Huddleston and Pullum (2002) also make similar claims, indicating that of-phrases are grammatically equivalent to adjectivals; on the other hand, the literature does not provide a fine-grained description of the differences between the two. Despite the linguistic fact of the difference in form (i.e., grammatical category), the clear-cut functional differences between them remain unclear. Bolinger (1977: x) maintains that "the natural condition of a language is to preserve one form for one meaning, and one meaning for one form." This study, therefore, extends our analysis that sheds light on the characteristics of of-phrases and uncovers the combination of two kinds of factors in the use of an experimental method. In this analysis, we focused special attention on the synonymous pair of of interest and interesting.

ExLing 2019: Proceedings of $10^{\text {th }}$ International Conference of Experimental Linguistics, 25-27 September 2019, Lisbon, Portugal 


\section{Methodology}

For this study, a paper-based experiment was conducted using a $2 \times 2$ factorial design crossing the Subject Type factor and the Modality factor. These variables refer to (i) whether a formal or real subject filled the Subject slot in their clauses and (ii) whether or the expressions co-occurred with modal verbs (e.g., may, must, will, respectively. These two factors will prove significant in the following analysis for the distinction between of-phrases and their equivalents.

Multiple choice experimental designs require four options rather than two. For this reason, we added interest and with interest, both of which have something in common with the target expressions from a semantic or structural viewpoint, yielding the alternatives (1: interest, 2: interesting, 3: of interest, and 4: with interest). We conducted a cloze test containing 16 target fragments in the small text passages, adapted from the British National Corpus, as shown in Examples $(2 a-d)$ :

(2) a. [Formal / Non-Modal] It is ( ) to compare Pausanias's account of Polygnotos's Troy at Delphi with two earlier vase pictures of the Sack.

b. [Formal / Modal] It will be ( ) to see whether these objectives are attained. As regards the first, it seems unlikely.

c. [Real / Non-Modal] The 1983 and 1987 general elections were ( ) for psephological as well as for political reasons.

d. [Real / Modal] A text of the past may be ( ) to a critic, a philosopher, and a historian, and each would discover his appropriate interest within it.

In this multiple-choice task, a questionnaire with 64 items (16 target fragments and 48 fillers) was administered to 30 subjects, 15 of whom were native speakers of American English and the other 15 were native speakers of British English (17 females, 13 males). ${ }^{1}$ The subjects, aged $20-50$ years, were asked to complete each sentence by choosing the most natural of the four expressions in the provided contexts as spontaneously as possible. As a result, we obtained a total of 480 sentence completion responses (16 fragments $\times 30$ participants) and conducted further quantitative analysis on these responses in terms of frequency. 


\section{Results and discussion}

Table 1 exhibits the frequency of analyzable completions produced in this experiment. It is shown that of interest and interesting display the highest frequencies.

Table 1. Frequency and percentage of the four expressions in this experiment.

\begin{tabular}{|l|l|l|}
\hline Expressions & Frequency & $\%$ \\
\hline interest & 2 & 0.4 \\
\hline interesting & 278 & 57.9 \\
\hline of interest & 196 & 40.8 \\
\hline with interest & 4 & 0.8 \\
\hline Total & 480 & 100.0 \\
\hline
\end{tabular}

We also explored the interaction between the factors in more detail. Table 2 shows the percentage of analyzable occurrences when presented with the Formal or Real subject and with and without modal verbs. (Table 2 focuses on the frequencies of interesting and of interest with respect to each factor.) The important point displayed in Figure 1 is that the use of the two expressions fluctuates according to the four experimental conditions. A decreased use of of interest can be observed under the Formal subject conditions (the total of the Formal/Non-Modal condition and the Formal/Modal one). However, the preference for the phrase increases under the Real/Non-Modal condition; its occurrence becomes very close to interesting. When the Real subject co-occurs with a Modal, the preference for of interest is strongly established.

Table 2. Frequency of interesting and of interest in this experiment.

\begin{tabular}{|l|l|l|}
\hline \hline & interesting & of interest \\
\hline Formal / Non-Modal & 95 & 23 \\
\hline Formal / Modal & 97 & 20 \\
\hline Real / Non-Modal & 67 & 52 \\
\hline Real / Modal & 19 & 101 \\
\hline \hline
\end{tabular}

Based on the results obtained from this experiment, two important implications follow. First, although the effect of subject type is greater than that of modality, each factor has a decisive effect on the choice between the paired items. Second, more importantly, these two factors reinforce one another in the use of synonymous expressions.

Another point that is evident from this study is that the participants' strong preference for of interest can also be seen in structures such as below:

(3) a. What happens in childhood is ( ) ...

b. The relative emphasis on neuroses in female GP referrals is ( )... 


\section{T. Fujiwara, F. Nakamura, D. Suzuki}

The use of of interest, thus, indicates a close relationship to the specification of the subject and the expression of modality, and more information is encoded in the of interest clause than in that of interesting. In terms of form and meaning, it is plausible that these characteristics of the phrase of interest are derived from its form-that is, from the fact that it is a (prepositional) phrase, not a word (adjective). Simply put, such a complex use of of interest has a close affinity to its phrase structure. This situation corresponds precisely to the predictions of the hypothesis of iconicity of complexity (cf. Haiman 1980, 1985). This idea also adheres to Lakoff and Johnson's principle, "more of form is more of content" in our conceptual system (Lakoff and Johnson 1980: 127).

\section{Conclusion}

To test the factors subject type and modality in isolation and in unison, an experimental technique was employed in this study. We generated four experimental conditions by manipulating these two factors. The results revealed a significant interaction between the factors in the choice of paired items, and we interpreted them from the iconic point of view.

\section{Notes}

We also explored regional differences in the use of of-phrases and their equivalents; however, it did not reach standard levels of significance.

\section{References}

Biber, D., Johansson, S., Leech, G., Conrad, S. 1999. Longman Grammar of Spoken and Written English. Harlow, Pearson.

Bolinger, D. 1977. Meaning and Form. London, Longman.

Haiman, J. 1980. The iconicity of grammar: Isomorphism and motivation. Language 56, 515-540.

Haiman, J. 1983. Iconic and economic motivation. Language 59, 781-819.

Huddleston, R. and Pullum, G.K. 2002. The Cambridge Grammar of the English Language. Cambridge University Press.

Lakoff, G., Johnson, M. 1980. Metaphors We Live By. University of Chicago Press.

Quirk, R., Greenbaum, S., Leech, G., Svartvik, J. 1985. A Comprehensive Grammar of the English Language. London, Longman. 